\section{hommes}

\section{Hommes \& migrations}

Revue française de référence sur les dynamiques

migratoires

1303 | 2013

Diasporas marocaines

\title{
Le Kaneka par ses acteurs
}

\section{François Bensignor}

\section{OpenEdition \\ Journals}

\section{Édition électronique}

URL : http://journals.openedition.org/hommesmigrations/2599

DOI : 10.4000/hommesmigrations.2599

ISSN : 2262-3353

\section{Éditeur}

Musée national de l'histoire de l'immigration

\section{Édition imprimée}

Date de publication : 1 juillet 2013

Pagination : 193-197

ISBN : 978-2-919040-23-0

ISSN : $1142-852 X$

\section{Référence électronique}

François Bensignor, «Le Kaneka par ses acteurs », Hommes \& migrations [En ligne], 1303 | 2013, mis en ligne le 22 janvier 2014, consulté le 22 septembre 2020. URL : http://journals.openedition.org/ hommesmigrations/2599; DOI : https://doi.org/10.4000/hommesmigrations.2599 


\title{
MUSIQUES
}

\section{LE KANEKA PAR SES ACTEURS}

\author{
FRANÇOIS BENSIGNOR
}

I 'exposition Kanak, l'Art est une parole, qui se Ltient au musée du Quai-Branly (15 octobre 2013-26 janvier 2014), est la plus importante réalisée depuis ces vingt dernières années sur la culture kanak.

Les 19 et 20 octobre, au théâtre Claude LéviStrauss du musée, a eu lieu KMuzik, conçu par quatre artistes parmi les plus emblématiques de la scène actuelle de Nouméa. Le 17 octobre, la Maison de la Nouvelle-Calédo-nie à Paris a présenté le livre Kaneka, musique en mouvement, qui retrace l'histoire de cette musique et brosse le portrait d'une cinquantaine de groupes.

Dans l'extrait publié ci-dessous, la parole d'artistes qui ont nourri cette musique en définit les contours sensibles et poétiques.

\section{Kaneka \& origines}

Moïse Wadra, artiste : "Dans le kaneka, chacun a son style."

Hervé Lecren, artiste : "Pour moi, le kaneka est multiple. Quand j'entends des éléments de la musique kanak, qu'il s'agisse de rythmes ou de mélodie, c'est du kaneka. Ce qui va donner la couleur kaneka à la musique, ce sont les timbres ainsi que les aspects rythmiques et mélodiques.

"Nous n'avons pas la même histoire entre les îles et la Grande Terre. Jean-Marie Tjibaou parle des 'coups de botte au derrière' et de 'la spoliation foncière' qu'ont subies les gens de la Grande Terre. Ce qui n'a pas eu lieu sur les îles. Aux îles, les gens n'ont aucun complexe pour chanter, alors que sur la Grande Terre, on chante souvent le dos tourné Le pilou se danse dans l'entre-soi, ce n'est pas un spectacle. Bien sûr, ça a changé, mais on a du mal à se réimprégner des chants aé aé sur la Grande Terre."

Emmanuel Tjibaou, directeur du Centre culturel Tjibaou : "Les groupes de la première vague du kaneka traitent essentiellement de la revendication identitaire: accession à la souveraineté, reconnaissance, nécessité de dire qui on est, pas seulement kanak, mais dire que l'on est de tel village, que l'on parle telle langue, etc. Ils parlent aussi de la 'justice coloniale' : beaucoup de gens ont fait de la prison au cours des événements, la justice d'alors était fortement en faveur du pouvoir en place.

“Les îles sont des 'réserves intégrales'. Elles ont été régentées par la religion. Ainsi, les thématiques religieuses y restent prédominantes: on chante la prière, la chefferie, beaucoup l'amour. Sur la Grande Terre, on est plus pudique de ce point de vue. Les gens de la Grande Terre ont subi la colonisation de plein fouet, avec le déplacement des clans, assignés dans des réserves, l'impôt de capitation, le travail obligatoire chez les colons. Toutes ces injustices font partie des thèmes abordés dans les années 
1980. Mon père avait 10 ans en 1946. Comme son père et ses aînés, il a vécu sous ce régime colonial."

\section{Les styles du nord de la Grande Terre}

Gilbert Tein, artiste : "Ici, le mot musique n'existait pas dans nos langues. On dit 'le roseau' (hango), avec lequel on fabrique la flûte; 'chanter' (kot) 'parler' (pala) ; 'rire' (naan) ; 'crier' (boua) ; 'danser' (pila) ; 'bruit' (goun) ; les percussions d'écorce (bwanjep), etc

"Dans nos traditions, la musique est liée aux cérémonies. Certaines danses de femmes ont disparu, parce qu'il n'y a plus d'occasion pour les interpréter. Les deuils des grands chefs n'ont pas lieu tous les jours. Or, en soixante-dix ans, on a le temps d'oublier certains éléments du rite, s'il n'y a pas de répétition intergénérationnelle. On a besoin de conserver tout cela.

"Un kaneka utile, rendant service à la culture kanak, devrait en revenir à une musique plus acoustique. Et aussi restituer à la culture coutumière la partie qui lui revient. L'igname est plantée et quand on la récolte, selon ce qu'elle a donné, on en mange une partie, on en vend une partie au marché et l'on garde le reste afin de la replanter. On ne rachète pas de semis. La musique devrait fonctionner comme cela. On vend ce qu'on peut vendre, mais ce qui reste, il faut le travailler afin de le replanter. Si l'on veut redonner de l'élan à la musique, il faut en soigner les semis à replanter.

"L'une des premières pistes de travail consiste à approfondir la structure formelle du kaneka. Les vieux commençaient par la voix. La seconde s'ajustait à la première et alors seulement les percussions démarraient. C'est cela qu'il nous faut retrouver dans le kaneka, de même que la conclusion sur un cri. II nous faut garder la spontanéité, la fraîcheur de l'expression naturelle."

Austien Junior Touyada, artiste : "Entre les groupes de kaneka des illes, du Sud et du Nord, on se retrouve surtout à travers la voix. Le chant révèle des traits communs à tous les styles du pays. En revanche, les rythmiques diffèrent, tant sur le plan du ressenti que du débit. Parfois, la différence entre deux rythmes peut paraitre assez subtile, mais dans le Nord, on reste sur des choses très simples: des battements à deux temps.

"Chaque région a son rythme. Par exemple, le rythme ayoii, très cadencé, est plutôt lent. Le nêên est le rythme d'une danse guerrière. Le cada est lié à une danse d'accueil, etc. Dans les traditions du Nord, le chant a une valeur première associée à un rythme. La beauté de la musique vient de la simplicité rythmique qui va mettre en valeur la voix. Une voix qui s'exprime d'une manière primaire. C'est cet esprit venu des chants aé aé que le kaneka tente de préserver."

\section{Musique des îles}

Édouard "Édou" Wamai, artiste : "Historiquement, les îles Loyauté ont reçu d'abord les influences de la culture polynésienne, notamment les rythmes. Ensuite, avec la religion protestante, les pasteurs anglophones y ont importé les chants grégoriens et les cantiques. De par ces influences, la 'musique des îles' a un caractère très mélodique, facilement adapté à l'oreille et au coeur. Les lignes mélodiques chantées à Maré, Lifou et Ouvéa, diffèrent peu de celles chantées par les Hawaïens, les Fidjiens ou les Tahitiens. Et la combinaison avec les mots de nos langues induit un univers rythmique particulier à notre manière de chanter."

\section{Paroles de Maré}

Moïse Wadra : "Un vieux part à la pêche. Il remplit d'eau sa gourde. Et quand le vent du Nord souffle sur l'embouchure, il en sort des sons, qui donneront naissance à plusieurs danses. Ainsi est née la mélodie.

"Nous sommes à la fois musiciens et danseurs. On n'a pas envie de séparer les deux. D'ailleurs, chez 
nous on ne parle pas de musique, on dit que c'est la danse de tel ou tel clan... C'est le neveu qui va faire la coutume pour demander de pouvoir interpréter telle ou telle danse.

“On appelle 'aloth' le bambou pilonnant. Quand on le joue, c'est la terre qui parle.

"À Maré, la frappe se décline en 3, 5 ou 7. Chez nous, les rythmes du cap dans les chants de Mebuet comptent 5 frappes : ce sont les danses guerrières, les danses des hommes.

"Nos chansons sont toujours des litanies. On commence toujours par le refrain.

"Les Anglais ont amené le solfège. Les anciens chantaient peut-être différemment, mais nous chantons comme les Anglais nous l'ont appris, à quatre voix : basse, ténor, alto, soprano (...). Nous, à Maré, pouvons mettre plein de voix dans une chanson : 5, 6 voix. Et on peut créer des nouveautés dans le rythme. Il y a une vraie créativité.

"Nous parlons toujours de l'esprit. L'arbre a son esprit. Le médicament que l'on en tire est son esprit.
Chez nous 'lan' (la clé) de la musique, c'est la sève de l'arbre."

Dick Buama, artiste : "Dans la langue de Maré, chanter se dit 'yéra', qui signifie 's'aimer'... À Maré, on chante pour s'aimer...

"Notre façon de chanter en chœur est un héritage des polyphonies traditionnelles, qui ont intégré les expressions des chants religieux protestants. Le chant polyphonique est toujours très vivant, dans les fêtes, les mariages. II se pratique par classes d'âge, à travers les rituels qui sont très nombreux.

"Participant à la coutume, les jeunes se forgent un répertoire en écoutant puis en chantant avec leurs aînés. C'est ce quifait office d'école de musique chez nous...

"À partir du moment où l'on est marié, on va chanter d'autres répertoires, comme le répertoire religieux, par exemple. L'apprentissage des chants passe là encore par les gens plus âgés, qui possèdent parfois des répertoires immenses.

"Dans la pratique du chant, chacun s'intègre natu- 


\section{MUSIQUES}

rellement selon sa voix : on sait ce qu'on a à faire. C'est une originalité que nous devons garder et qui a toute sa place dans notre culture."

\section{Paroles de Lifou}

Édouard "Édou" Wamai, artiste : "Le kaneka s'est formulé à partir de rythmes de danses traditionnelles. Le fehoa s'appuie sur des histoires chantées, que l'on mime. On les raconte avec toutes les expressions du corps, des voix et des rythmes. Dans le fehoa se retrouve une grande diversité d'éléments : la tristesse, la joie, la guerre, les lamentations, etc. Cette danse raconte toutes les phases de la vie et l'on y retrouve tous les aspects des rythmes et danses que nous jouons: bua, drui, lamentations, etc. Le fehoa est une création des anciens d'hier. Quand l'écriture est arrivée, on a cessé de chanter nos contes en les mimant à travers la danse, pour essayer de les écrire. Ainsi les danses se sont-elles spécialisées: on danse la guerre, on danse l'igname, etc., mais on ne danse plus l'épisode de la vie qui va de la naissance à la mort.

Le bua est la danse qui exprime la guerre. Le drui est lié à la création de la case.

"Lecapapprochetouslesélémentsdel'expression par la danse à sa façon. À l'origine, seuls les hommes pratiquaient la danse, afin d'expliquer deschoses bien spécifiques: le cycle de l'igname, la construction de la case, le vol de l'oiseau, etc. Mais les femmes n'avaient pas leur place dans ces danses. Du coup, elles ont créé une façon de danser entre elles, à la périphérie des danses des hommes, afin de pouvoir elles aussi s'exprimer. C'est cette danse qui s'appelle le 'cap'. On peut considérer le cap comme la revendication de leur place dans la société, mais aussi comme une façon de se montrer afin d'être remarqué. Le cap est donc un espace de parole créé par les fermmes. Comme l'expression des femmes dans le cap peut être assez provocante, les hommes, attirés, se sont introduits dans la danse. Pour danser le cap, hommes et femmes forment un cercle, au milieu duquel dansent une femme et un homme, qui font un aller-retour. II y a une certaine sensualité dans ce jeu de la danse. Après les grandes cérémonies comme celles des grands mariages, lorsque les danses sacrées, très représentatives et bien coordonnées, sont terminées, le cap rassemble toutes les générations des deux sexes pour un moment d'amusement et de convivialité. Mais, à la différence 
Édouard “Édou” Wamai ৫ François Bensignor

du slow où l'on susurre des mots doux à l'oreille de l'autre, dans le cap l'homme et la femme s'interpellent à pleine voix, au vu et au su de tous ceux qui participent à la danse: 'Je voulais t'appeler, mais je n'ai pas ton numéro ! - Si tu danses bien avec moi, je te le donnerai, répond la fille. Ce qui peut amener à des joutes verbales entre garçons pour danser avec une même fille. Le cap est un espace très joyeux, issu d'un espace très codifié dans le respect des Grand Chefs et de la hiérarchie des clans. C'est un peu notre 'boum'..."

\section{/// REPÈRES}

- Kanak, l'Art est une parole, musée du QuaiBranly du 15 octobre 2013 au 26 janvier 2014

- 19 et 20 octobre, au théâtre Claude LéviStrauss du musée du Quai-Branly : K Muzik, le meilleur de la musique kanak, avec Paul Wamo, chef de file du slam en Nouvelle-Calédonie ; Gulaan, artiste d'un nouveau folk mélanésien; Ykson, musicien de blues aux accents de ragga ; Boagan, artiste entre rock et reggae. Ces musiciens sont accompagnés de deux danseurs du Wetr Kréation et d'une création vidéo.

- François Bensignor (dir.), Kaneka, musique en mouvement, Nouméa, Poemart / ADCK-CCT, 2013.

- Maison de la Nouvelle-Calédonie, 4 bis, rue de Ventadour, 75001 Paris - Tél. : 0142867000 Web : www.mncparis.fr. 